\title{
Servikal dejeneratif disk hastalığı: genel bakış ve epidemiyoloji
}

\author{
Cervical degenerative disc disease: overview and epidemiology
}

\author{
İsmail Oltulu, Gürsel Saka
}

Fulya Ortopedi ve Omurga Merkezi, İstanbul

\begin{abstract}
Servikal dejeneratif hastalık veya servikal spondilozis terimi, kabaca yaşla birlikte servikal omurgada oluşan değiş̧iklikleri ifade etmektedir. Spondilozis, vertebra korpusunda dejeneratif spur formasyonları ile birlikte görülen disk ve bağlardaki patolojik değişiklikleri içine alan omurgadaki yaşlanmaya bağlı değişikliklerdir. Servikal omurgada dejeneratif değişiklikler; yaşlanmanın yanı sıra travma, genetik faktörler ve çevresel faktörlerden de etkilenir. Servikal omurgadaki yaşa bağlı dejeneratif değişikliklerin çoğu 5 . dekaddan sonra oluşur; sıklıkla C5-C6 disk mesafesinde görülür ve çoğunluğu asemptomatik seyreder. Servikal dejenerasyonla ilişkili semptomlar genel popülasyonun \%5 kadarında herhangi bir zamanda görülmekte ve aksiyel boyun ağrısından, servikal radikülopati ve spondilotik miyelopatiye uzanan geniş bir spektrumda yer almaktadır.
\end{abstract}

Anahtar sözcülkler: dejeneratif disk hastalığı; servikal miyelopati; servikal spondiloz

\begin{abstract}
Age related degenerative changes in cervical spine are defined as cervical degenerative disease or cervical spondylolysis. Spondylolysis is the name of pathological changes of disc and ligaments within spur formation of vertebral body related to the aging of spine. These degenerative changes in cervical spine can occur due to genetic factors, trauma and other life characteristics besides aging. Age related degenerative changes are mostly seen after fifth decade; these are seen usually at C5-C6 disc, and generally asymptomatic. The clinical symptoms seen any time in $5 \%$ of general population, and it can evolve in a broad spectrum from axial neck pain to cervical radiculopathy and spondylotic myelopathy.
\end{abstract}

Key words: degenerative disc disease; cervical myelopathy; cervical spondylolysis

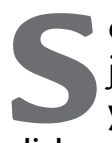

ervikal spondiloz, intervertebral disklerin dejenerasyonu sonucu servikal omurgada oluşan yaşlanmadır. ${ }^{[1]} \mathrm{Bu}$ süreçte, servikal omurgada disk mesafesinde kısalma, bağlarda kalınlaşma, ligamentöz ve segmenter instabilite gelişmesi, faset eklemlerde artroz ve lordoz kaybı görülür. ${ }^{[1]}$ Dejeneratif disk değişiklikleri, sıklıkla taşma (bulging), protrüzyon, ekstrüzyon, sekestrasyon şeklinde görülmektedir. Servikal diskler, anteriorda posteriora göre daha kalındır ve bu durum normal lordozun oluşmasını sağlar. Dejeneratif süreçte, öncelikle diskin anteriorunda yükseklik azalmakta ve lordoz kaybı oluşmaktadır. Yaşlanmayla birlikte süreç ilerler ve dejeneratif değişikliklere bağı aksiyel boyun ağrısı ve/veya disk hernilerine, intraspinal kanal ve foraminal darlıklara, sekonder radikülopati veya miyelopati semptomlarına yol açar.

\section{PATOFIZYOLOJi}

Intervertebral disk vertebral gövdeler arasında artikülasyondan sorumlu olmakla birlikte, silindirik ve fibrokartilajenöz yapıdadır. Fleksiyon, ekstansiyon ve rotasyona izin vermektedir. Makroskobik olarak anulus fibrozis denilen bir dış tabaka ve santralde lokalize nükleus pulpozus denilen bir iç tabakadan oluşmaktadır. ${ }^{[2]}$ Intervertebral disk, kraniyal ve kaudalde kemik ve hiyalin kartilajdan oluşan endplate ile çevrilidir. ${ }^{[2]}$ Bunların en temel majör görevlerinden birisi, yüksek oranda hidrate nükleus pulpozusun komşu vertebraya fitıklaşmasını önlemektir. ${ }^{[2]}$ Yaşlanmayla birlikte, intervertebral diskin ekstrasellüler matriks kompozisyonunda, hücre içeriğinde değişiklikler olur. ${ }^{[3]}$ Ancak, bu değişiklikler sadece lumbar omurgada gösterilmiştir.

- Illetişim adresi: Op. Dr. İsmail Oltulu, Dikilitaş Mah. Ayazmadere Cad. Yeşilçimen Sok. No: 9/3 Kat: 3, Fulya, Beşiktaş, İstanbul Tel: 0212 - 2276338 e-posta: ioltulu@hotmail.com

- Geliş tarihi: 5 Nisan $2017 \quad$ Kabul tarihi: 5 Nisan 2017 
Servikal dejeneratif disk hastalığına neden olan patofizyolojik mekanizma hakkında, tam bir görüş birliği olmamakla birlikte, birkaç varsayım geliştirilmiştir. Güncel yaklaşıma göre yaşlanmanın normal bir parçası olarak düşünülmekle birlikte, bazı meslekler, tekrarlayıcı hareketler, travma gibi nedenler süreci hızlandırabilmektedir. Sadece tek bir faktörün dejeneratif süreci tetikleme şansı yoktur. Daha doğrusu, normal yaşlanma sürecinin birçok faktörü servikal spondilolizisi etkilemektedir.

Hayatın 3. dekadına ulaşıldığında, sıklıkla intervertebral diski çevreleyen periferal kan desteğinde azalma görülür. Bu durum, vertebral endplate'in sklerozuyla birlikte intervertebral disk içerisindeki hücrelere diffüzyonun bozulmasına neden olur. Bunun gibi çevresel faktörler, hücrelerin yaşlanmasına ve daha az proteoglikan salgılanmasına neden olmaktadır. Hücresel yaşlanma ve proteoglikan seviyesinde azalma, diskin hidrasyonunu azaltarak diskin yük taşıma kapasitesi ve yapısal özelliklerini değiştirir. Yükün anulüs fibrozise transfer olması, disk kollapsına ve potansiyel herniyasyona katkıda bulunan fissüre ve elastikiyet kaybına neden olmaktadır. Disk yüksekliğindeki kayıp, aynı zamanda hareket artışına ve posterior faset eklemlerde yıpranmaya, ligamentum flavumu da içeren posterior ligamentöz yapılarda hipertrofiye neden olur. İnflamasyon ve aşırı hareket, disk kenarlarında, unkovertebral eklemlerde ve fasetlerde osteofit oluşumuna neden olur. Osteofitler, herniye disk materyalleri veya hipertrofiye yumuşak doku yapıları, sinir köküne veya spinal korda bası yaparak radiküler ağrıya veya miyelopatiye neden olabilmektedir.

Servikal omurgada dejenerasyon, spinal kord veya sinir kökünde bası yoksa, sadece boyun ağrısı ile kendini gösterebilir. Bu dejenerasyon, sinir kökünde ekstrensik basıya bağlı inflamasyon nedeniyle, oksipital bölgede, boynun posteriorunda, omuzda veya kolda radiküler tarzda ağrıya neden olmaktadır. Benzer semptomlar, herniye diskten salgılanan interlökinler, tümör nekroz faktör-alfa ve substans $P$ gibi inflamasyon nedeniyle oluşan sitokinler sayesinde de olur. ${ }^{[4]}$ Dejeneratif değişiklikler her seviyede olmakla birlikte, en sık C5-C6'da sırasıyla, C6-C7 ve C4-C5'te görülür. Anterior kord kompresyonu, sıklıkla herniye nükleus pulpozus (yumuşak disk herniyasyonu, sert disk herniyasyonu), endplate osteofitleri ve posterior bağ ossifikasyonu (OPLL) nedeniyle olur. Posterior impingment sıklıkla ligamentum flavumun katlanmasıyla ve faset artropatisi nedeniyle oluşmaktadır. Birçok durumda, hem anterior hem de posterior proçesler, spinal kanalda pincer efekti diye adlandırılan daralmaya neden olur. ${ }^{[4]}$

\section{NÜKLEUS PULPOZUSUN HERNIYASYONU}

Bazı genç bireylerde, nükleus pulpozusun prolapsusundan önce anulus fibroziste yırtık oluşur. Böyle durumlarda, lumbar omurgadaki disk herniyasyonuna benzer şekilde, disk içeriğinin spinal kanal veya foramene prolapsusu olabilmektedir. Servikal sinir kökündeki mekanik yer değiştirmenin yanı sıra, nükleus dokusundan salınan kimyasal mediyatörler de radikülopatiye, duyusal ve motor disfonksiyonlara neden olmaktadır. Servikal radikülopatili 736 hastayı içeren bir derlemede Henderson, \%94,4 hastada radiküler kol ağrısı, $\% 85,2$ 'sinde duyu anomalileri, \%68'inde motor disfonksiyon, \%9,7'sinde kronik baş ağrısı ve \%1,3'ünde servikal anjina (sol taraflı göğüs ve kol ağrısı) bildirmiştir. ${ }^{[5]}$ C5-C6 seviyesi, disk herniyasyonunun en fazla olduğu seviyedir ve sıklıkla C6 sinir kökü etkilenir.

\section{SERVIKAL SPONDILOLIZIS: AKSIYEL BOYUN AĞRISI VE RADIKÜLOPATi}

Servikal dejenerasyonun çok ileri aşamalarında, disk mesafesinde azalma, disk bulging'i, osteofit formasyonu ve faset artrozu, radiküler semptomlara neden olan sinir kökü sıkışmasına neden olabilmektedir. Belirgin bir bası olmadığında, bu gibi dejeneratif değişiklikler aksiyel boyun ağrısı semptomlarına neden olur.

Sinovertebral sinirin dalları intervertebral diski innerve ederken, nosiseptif fiberler kapsül ve faset eklemde bulunmaktadır. Nöral foramendeki stenoz ağrı, duyu ve motor kayıplar gibi disk herniyasyonunun oluşturduğu radiküler semptomlara benzer şekilde semptomlar oluşturur. Üst servikal vertebralardaki dejeneratif değişiklikler, boyun veya kulağa yayılan suboksipital ağrı oluşturur. Spondilotik radikülopatide semptomlar, yumuşak disk hernisine göre sıklıkla daha kademeli bir şekilde oluşur. Spondilotik radikülopatide, birçok seviyenin tutulmasının yanında, hastalarda büyük oranda her iki ekstiremitede de semptomlar vardır. ${ }^{[6]}$ Servikal radikülopatinin ayırıcı tanısı; epidural abseler, rotator cuff / omuz patolojileri, periferal sinir sıkışma sendromları, herpes zoster, kardiyak iskemi veya torasik outlet sendromunu içerir.

\section{SERVIKAL SPONDILOTIK MIYELOPATI (SSM)}

Servikal omurga normalde lordotiktir ve yaşla ilişkili dejeneratif değişiklikler, hiperlordoz, skolyoz ve belirgin kifozla sonuçlanabilir. Servikal spondilitik miyelopatili hastada cerrahi tedavi planlanırken, hastanın servikal dizilimi göz önünde bulundurulmalıdır. Ames'in hipotezinde, servikal hiperkifozun miyelopati şiddetine ve patogenezine katkıda bulunduğu bildirilmiştir. Kifoz; dentat bağ ve sinir kökleri tarafindan tutulan korda 
longitudinal gerilemeye bağlı, anterior kord patolojisine neden olur. ${ }^{[7]}$ Spinal kordda gerilme; nöral kayba, demiyelinizasyona, küçük damarlardaki düzleşmeye bağlı kan desteğinde azalmaya neden olan intramedüller basınçta artışa neden olur.

Servikal miyelopatinin tanınması, başlangıçta semptomların varlığı ile olur. Boyun ağrısı ve sertlik, hissizlik ve ellerde yanma, güçsüzlük, bilateral kollarda parestezi, yürüme bozuklukları ve/veya L'Hermitte's fenomeni bulguları geliştiği zaman, hastaların medikal müdahaleye ihtiyaçları olabilir. ${ }^{[8]}$

Otonomik semptomlar; başlangıçta olmayan, diğer semptomlara eşlik eden idrar sıklığında artış, idrar kaçırma ve üriner inkontinansı içerir. ${ }^{[9]}$

Bazı çalışmalarda, belirgin yürüme bozukluğu, servikal spondilotik miyelopati (SSM)'nin en sık klinik prezantasyonu olarak bildirilmiştir ve spastik yürüyüş ilk belirti iken, bunu üst ekstremite güçsüzlüğü ve ellerde ince motor kontrol kaybı izler. ${ }^{[10]}$ Yürüme bozukluğu geniş bir klinik spektruma sahiptir. Belirgin spastik paraparezi en sık klinik prezantasyondur; bacaklarda güçsüzlük ve sadece bir miktar kasılma ile birlikte normal hızda hafif yürüme defisitini (hafif aksama) içerir. Benzer şekilde, ellerde fonksiyonları etkilemeyen hafif duyu kaybından, bağımsız olarak kendi günlük aktivitelerini yapamayacak derecede fonksiyon kaybına kadar, değişen derecelerde klinik tablolar oluşur.

Spinal kord disfonksiyonunu doğrulamak için nörolojik muayene kullanılır. Spinal kord disfonksiyonunun yaygınlığını tespit etmek için kullanılan klinik bulgular; kortikospinal yol bulguları, hiperrefleksi, pozitif plantar cevap, ataksik yürüme, spastisite/klonus ve Hoffman'ın bulgusunu içerir.

Spinal kord disfonksiyonu, Asya popülasyonunda, sıklıkla posterior longitudinal bağ ossifikasyonuna bağlı stenoza ve miyelopati oluşumuna katkıda bulunur. Miyelopatinin histopatolojisi; aksonal demiyelinezasyon, hücre nekrozu, skarlaşma ve gri tabakada kavitasyona neden olan anterior kordda uzamış mikrovaskülarite tutulumunu içerir. ${ }^{[11]}$

Miyelopati, sıklıkla 55 yaşın üstündeki hastalarda görülen en yaygın spinal kord disfonksiyonu nedenidir. Servikal miyelopati semptomları, sıklıkla hayatın 6. dekadında görülmekte ve en sık C5-C6, sırasıyla C4-C5 ve C6-C7'de görülmektedir. Semptomlar, bireylere göre değişken ve uzun yıllarca hafif ve stabil seyirli olabilir. Crandall ve Batzdorf, servikal miyelopatili 62 hastayı içeren çalışmalarında, hastaların sadece \%38'inde radiküler semptom, \%50'den azında boyun ağrısı semptomları saptamışlardır. Sadece, hastaların $\% 27$ 'si Lhermittes' fenomeni sergilemişlerdir. ${ }^{[12]}$
Çoğu hasta, asemptomatik olmakla birlikte fizik muayene bulgusu da sergilememiştir. Bu gibi durumlarda omurga uzmanlarına yönlendirilen hastaların manyetik rezonans (MR) görüntülerinde insidental olarak miyelomalazi saptanmaktadır. Clark ve Robinson, servikal miyelopatili 120 hastayı içeren derlemelerinde, hastaların \%75'inde uzun süre stabil durumdan sonra adım adım kötüleşme bildirmişlerdir. Hastaların \%20'sinde düzenli ve yavaş bir ilerleme, \%5'inde ise fonksiyonlarda hızlı bir kötüleşme bildirmişlerdir. ${ }^{[13]}$

SSM, 1966 yılında Crandall ve Batzdorf tarafindan beş katogoride tanımlanmıştır. ${ }^{[12]}$ En sık şekli, kortikospinal ve spinotalamik traktı tutan transvers lezyon sendromudur. Semptomlar, üst motor nöron bulgularını, alt ekstremite spastisitesi ve güç kaybını içermektedir. Santral kord sendromu, santral gri tabakanın kompresyonuna bağlı gelişir ve ağrılı distezi ile birlikte üst ekstremitede motor ve duyu tutulumuna neden olur; alt ekstremite genellikle korunmuştur. BrownSequard sendromu, aynı tarafta motor kayıp ve karşı tarafta ısı ve ağrı duyusu kaybı ile karakterizedir. Bu miyelopatik sendrom, en iyi geri dönüş prognozuna sahiptir. Motor sistem sendromu, anterior horn hücrelerinin ve kortikospinal trakt üzerindeki pür anterior basıya bağlı oluşur. Bu durumun semptomları, yürüme bozuklukları ve güçsüzlükle kısıtlıdır. Brakiyalji kord sendromu, radikülopati ve miyelopati semptomlarının kombinasyonundan oluşur. Hastalar, üst ekstremitede güçsüzlükle birlikte radiküler ağrıya ve alt ekstremitede spastisiteye sahiptir.

Ferguson ve Caplan, SSM'yi daha basit bir şekilde dört gruba ayırmışlardır. Bu primer olarak; uzun trakt semptomları içeren mediyal sendromu, lateral sendromu, mediyal ve lateral sendromu ve kord iskemisiyle sonuçlanan hızlı ilerleyen bir form olan vasküler sendromu içermektedir. Ferguson ve Caplan sisteminde en sık görüleni, mediyal/lateral sendrom formudur. ${ }^{[14]}$

\section{SERVIKAL DEJENERATIF DISK HASTALIĞININ SINIFLANDIRILMASI}

Her ne kadar yazarlar SSM'yi kategorize etmeye çalışsalar da, günümüze kadar ideal bir sınıflaması olmamıştır. İdeal sınıflama sistemi, hekimler arasında iletişimi ve enformasyonu kolaylaştıracak şekilde kapsamlı ama basit olmalıdır. Hilibrand, dejenerasyonun radyolojik işaretlerine dayalı, kısmen basit bir üç aşamalı dereceleme skalası tanımlamıştır. ${ }^{[15]} \mathrm{Bu}$ sistem, hastalığın şiddetini kategorize etmek için disk yükseklik kaybının yanı sıra osteofit varlığına dayandırılmaktadır. Hilibrand değerlendirme skalasını radyografik görüntülemelere göre yaparken, bunu izleyen sınıflamalar MR'ı kullanmıştır. Kolstad, nükleus sinyal 
intensitesi, disk proplapsusu ve kemik iliği sinyal intensitesini içeren üç faktöre dayalı sistemi tasarlamıştır. ${ }^{[16]}$ Kolstad'ın sistemi, 12 kapsamlı kategoriyi (A dan L'ye) içerir. Sınıflama, oldukça kompleks ve interobserver güvenirliliği orta derecede gösterilmiştir.[16] Miyazaki, servikal spondilozis için çok yakın zamanlı MR temelli bir derecelendirme sistemini tanımlamıştır. ${ }^{[17]}$ Derecelendirme, diskin T2 ağırlıklı MR görüntülerine dayanarak, beş aşamada yapılmıştır. Bu sınıflamanın yaratıcıları, servikal disk dejenerasyonu tanımlanmasını standardize etmede güvenilir, basit bir sınıflama olduğunu düşünmektedir.

SSM için en sık kullanılan iki ölçüm yöntemi, JOA (Japanese Orthopedic Association) skalası ve Nurick derecelendirmesidir. Her ikisi de, nörolojik bulguları ve semptomları, yürümeyi, alt ekstremite fonksiyonlarını, el fonksiyonlarını ve mesane kontrolünü ölçmektedir. Her ikisi de sık kullanılmakla birlikte, özellikle hafif SSM'nin şiddet aralığını belirlemede duyarlılıkları düşüktür. Neck disability Index ve SF-36 (Short Form Health Survey), hastaların kendilerine yeterlilik fonksiyonlarını ölçmek için servikal omurga grupları tarafından da geçerli görülmüş değerlendirme yöntemleridir. ${ }^{[18,19]}$

Sınıflamaların hiçbiri doğrulanamamıştır; dahaSı, günümüzde tedaviyi yönlendirebilecek ya da servikal dejeneratif disk hastalığının doğal seyrini ya da prognozunu tahmin edebilecek herhangi bir sınıflama bulunmamaktadır.

Servikal miyelopatinin, erken evrelerdeki hafif belirsiz bulgulardan dolayı, doğru epidemiyolojisi tam olarak bilinmemektedir.

\section{RISK FAKTÖRLERi}

Servikal dejeneratif hastalığın kötüleşmesi veya gelişimi açısından risk faktörleri son dönemde aydınlanmıştır. Bazı risk faktörleri belirlenmiş olsa da, bunlarla semptomatik servikal dejenerasyon arasında korelasyon kurulamamıştır. Dejeneratif sürecin hızlanmasında aktif rol oynayan tahmini risk faktörleri; ağır işte çalışma, nikotin kullanımı, rugby ya da futbol oyuncusu olma ve konjenital servikal kanal darlığıdır. Birçok medikal durumda olduğu gibi, genetik yatkınlık da dejeneratif sürecin etkilenmesinde önemli rol oynayabilmektedir. ${ }^{[20,21]}$ Birçok meslek sahibi servikal spondilozis açısından artmış risk taşır. Bunlar arasında; ağır el işçileri, tarım işçileri, diş hekimleri, at jokeyleri ve savaş uçağı pilotlarını sayabiliriz. ${ }^{[22]}$

Daha önceki bir lumbar radikülopati öyküsünün semptomatik servikal dejenerasyonla birlikteliği doğrulanmıştır. Radhakrishnan, servikal radikülopatili hastaların \%41'inde daha önce bir lumbar radikülopati öyküsü olduğunu bildirmiştir. ${ }^{[6]}$ Uzun zamandır, sigara içiciliğinin dejeneratif süreci hızlandırdığı düşünülüyor olsa da, yakın zamanlı çalışmalar bu ilişkiyi gösterememiştir. Çok sigara içen ve içmeyen asemptomatik 200 kişinin direkt grafi ile incelendiği bir çalışmada, dejeneratif servikal hastalık açısından istatiksel olarak anlamIı bir fark bulunamamıştır. ${ }^{[23]}$ Ek olarak, daha önceki çalışmalarda, lumbar spondiloliziste genetik faktörlerin sigaradan daha etkili olduğu bildirilmiştir. ${ }^{[24]}$

Konjenital dar kanal, spinal kordun transvers alanı, kanal darlığının derecesi ve OPLL'nin miyelopati gelişimini etkilediği bulunmuştur. ${ }^{[24]}$

\section{TEDAVI SEÇENEKLERi}

Aksiyel boyun ağrısı ve servikal spondilotik radikülopatinin başlangıç tedavisi; kısa süreli istirahat, ağrı kesici ve NSAii tedavisi, fizik tedavi ve hasta eğitimini içerir. Çoğu olguda semptomlar, konservatif tedavi sonrasında kısa sürede gerilemektedir. Konservatif tedaviye yanıt vermeyen hastalarda cerrahi tedavi düşünülmelidir. Konservatif tedavi başarısızlığı \%20 -30 arasında tahmin edilmektedir. ${ }^{[25]}$ Üç ay konservatif tedaviye cevap vermeyen veya nörolojik kötüleşme olan servikal radikülopati hastalarında cerrahi tedavi düşünülmelidir. ${ }^{[25]}$ Nörolojik kötüleşme olan hastalar ve radyolojik olarak miyelomalazi görüntüsü olan çoğu hastalarda, miyelopati semptomları olsun ya da olmasın cerrahi tedavi düşünülmelidir. ${ }^{[25,26]}$ Servikal disk dejenerasyonu için cerrahi hedef, ağrının giderilmesi, daha fazla ilerlemesinin engellenmesi ve mümkünse radiküler veya miyelopatik semptomların düzelmesidir.

Aksiyel boyun ağrılı hastalarda, anterior servikal diskektomi ve füzyon uygun bir cerrahi yöntem olarak düşünülmektedir. ${ }^{[25]}$ Servikal radikülopati, anterior servikal diskektomi ve füzyon ile veya posterior laminotomi-foraminotomi ile tedavi edilebilir. Her iki prosedür için benzer sonuçlar bildirilirken; radiküler ağrıya aksiyel boyun ağrısı eşlik eden hastalarda anterior füzyon daha uygun olabilir. Fokal stenoza bağlı miyelopatisi olan veya eşlik eden kifozu olan hastalar, diskektomi ve korpektomiyi içeren anterior füzyon prosedürleri ile tedavi edilmektedir. ${ }^{[25]}$ Laminektomi ve füzyon veya servikal laminoplasti, çok seviyeli darlıklarda, konjenital dar kanalda veya daha önce anterioru yapılmış olan hastalarda uygulanabilir. ${ }^{[27]}$ Servikal radikülopati ve miyelopati için, cerrahi tedavi sonuçları doyurucudur. Wang, komplikasyon ve mortalitenin yaşlı hastalarda, miyelopatik hastalarda ve posterior servikal cerrahi yapılan hastalarda daha fazla olduğunu bildirmiştir. ${ }^{[28]}$ Yakın zamanda; hareketin korunması prensibi, teknolojik gelişime de paralel olarak servikal disk protezlerinin oluşumunu 
sağlamıştır. Servikal disk protezleri, servikal füzyon prosedürleri ile aynı dekompresyonu sağlarken, füzyonla ilgili komplikasyonları ve komşu segment dejenerasyonunu kısıtlamayı amaçlar. Radikülopati ve miyelopati için yapılan ileriye dönük çalışmalarda da, artroplasti ve füzyon için benzer sonuçlar bildirilmiştir. ${ }^{[29,30]}$ Riew, miyelopati semptomları nedeniyle servikal artroplasti yapılan hastaların sonuçlarını bildirmiştir. Bu çalışmada, protez yapılanlarla artrodez yapılanlar arasında, iki yıllık takipte, omuz ağrısı, boyun ağrısı, veya SF-36 skorlarında farklılık bulunmamıştır. Ek olarak artroplasti yapılan grupta, hiçbir hastada miyelopatik semptomlarda artış olmamıştır. ${ }^{[29]}$ Heller, ileriye dönük randomize çok merkezli çalışmada, artroplasti ile füzyonu karşılaştırmıştır. İki yılık takip sonrasında, disk protezi yapılan hastalarda neck disability skorlarının daha iyi olduğu ve işe erken dönüş olduğu, ciddi komplikasyon açısından iki grup arasında fark bulunmadığını bildirilmiştir. ${ }^{[30]}$

\section{SONUÇ}

Dejeneratif servikal süreç, 50 yaşın üzerinde neredeyse her bireyde görülen, yaşlanmanın normal bir sürecidir. Toplumun çoğunluğu hayatının bir döneminde boyun ağrısı yaşasa da, bunların çoğunda servikal dejeneratif değişiklik asemptomatiktir. Bazı bireylerde, aksiyel boyun ağıssı ve servikal radikülopatiyi içeren semptomlar çok belirgin olabilir. Dejeneratif değişiklikler belirgin stenozla sonuçlanırsa, miyelopati gelişebilir. Semptomların çoğu konservatif tedaviyle geriler; ancak bu tedavinin başarısız olduğu hastalarda ve progresif nörolojik defisit varlığında cerrahi tedavi düşünülmelidir.

\section{KAYNAKLAR}

1. Montgomery DM, Brower RS. Cervical spondylotic myelopathy. Clinical syndrome and natural history. Orthop Clin North Am 1992;23(3):487-93.

2. Taylor JR, Twomey LT. Growth of human intervertebral discs and vertebral bodies. J Anat 1988;120:49-68.

3. Gruber HE, Hanley EN Jr. Ultrastructure of the human intervertebral disc during aging and degeneration: comparison of surgical and control specimens. Spine (Phila Pa 1976) 2002;27(8):798-805.

4. Gooding MR. Pathogenesis of myelopathy in cervical spondylosis. Lancet 1974;16;2(7890):1180-1.

5. Henderson CM, Hennessy RG, Shuey HM Jr, Shackelford EG. Posterior-lateral foraminotomy as an exclusive operative technique for cervical radiculopathy: a review of 846 consecutively operated cases. Neurosurgery 1983;13(5):504-12.

6. Radhakrishnan K, Litchy WJ, O'Fallon WM, Kurland LT. Epidemiology of cervical radiculopathy. A population-based study from Rochester, Minnesota, 1976 through 1990. Brain 1994;117(Pt 2):325-35.
7. Ames CP, Blondel B, Scheer JK, Schwab FJ, Le Huec JC, Massicotte EM, Patel AA, Traynelis VC, Kim HJ, Shaffrey $\mathrm{CI}$, Smith JS, Lafage V. Cervical radiographical alignment: comprehensive assessment techniques and potential importance in cervical myelopathy. Spine (Phila Pa 1976) 2013;15;38(22 Suppl 1):S149-60. Crossref

8. Gemici C. Lhermitte's sign: review with special emphasis in oncology practice. Crit Rev Oncol Hematol 2010;74(2):7986. Crossref

9. Hattori T, Sakakibara R, Yasuda K, Murayama N, Hirayama K. Micturitional disturbance in cervical spondylotic myelopathy. J Spinal Disord 1990;3(1):16-8.

10. Gorter K. Influence of laminectomy on the course of cervical myelopathy. Acta Neurochir (Wien) 1976;33(3-4):265-81.

11. Breig A, Turnbull I, Hassler O. Effects of mechanical stresses on the spinal cord in cervical spondylosis. A study on fresh cadaver material. J Neurosurg 1966;25(1):45-56. Crossref

12. Crandall $\mathrm{PH}$, Batzdorf $U$. Cervical spondylotic myelopathy. J Neurosurg 1966;25(1):57-66. Crossref

13. Clarke E, Robinson PK. Cervical myelopathy: a complication of cervical spondylosis. Brain 1956;79(3):483-510.

14. Ferguson RJ, Caplan LR. Cervical spondylitic myelopathy. Neurol Clin 1985;3(2):373-82.

15. Hilibrand AS, Carlson GD, Palumbo MA, Jones PK, Bohlman $\mathrm{HH}$. Radiculopathy and myelopathy at segments adjacent to the site of a previous anterior cervical arthrodesis. J Bone Joint Surg Am 1999;81(4):519-28.

16. Kolstad F, Myhr G, Kvistad KA, Nygaard OP, Leivseth G. Degeneration and height of cervical discs classified from MRI compared with precise height measurements from radiographs. Eur J Radiol 2005;55(3):415-20. Crossref

17. Miyazaki M, Hong SW, Yoon SH, Morishita Y, Wang JC. Reliability of a magnetic resonance imaging-based grading system for cervical intervertebral disc degeneration. J Spinal Disord Tech 2008;21(4):288-92. Crossref

18. Hirabayashi K, Miyakawa J, Satomi K, Maruyama T, Wakano K. Operative results and postoperative progression of ossification among patients with ossification of cervical posterior longitudinal ligament. Spine (Phila Pa 1976) 1981;6(4):354-64.

19. Nurick $S$. The pathogenesis of the spinal cord disorder associated with cervical spondylosis. Brain 1972;95(1):87-100.

20. Taitz C. Osteophytosis of the cervical spine in South African blacks and whites. Clin Anat 1999;12(2):103-9. Crossref

21. Sambrook PN, MacGregor AJ, Spector TD. Genetic influences on cervical and lumbar disc degeneration: a magnetic resonance imaging study in twins. Arthritis Rheum 1999;42(2):366-72. Crossref

22. Takamiya $Y$, Nagata $K$, Fukuda $K$, Shibata $A$, Ishitake $T$, Suenaga T. Cervical spine disorders in farm workers requiring neck extension actions. J Orthop Sci 2006;11(3):235-40. Crossref

23. Battié MC, Videman T, Gill K, Moneta GB, Nyman R, Kaprio J, Koskenvuo M 1991 Volvo Award in clinical sciences. Smoking and lumbar intervertebral disc degeneration: an MRI study of identical twins. Spine (Phila Pa 1976) 1991;16(9):1015-21.

24. Matsunaga S, Nakamura K, Seichi A, Yokoyama T, Toh S, Ichimura S, Satomi K, Endo K, Yamamoto K, Kato Y, Ito T, Tokuhashi Y, Uchida K, Baba H, Kawahara N, Tomita K, Matsuyama $\mathrm{Y}$, Ishiguro $\mathrm{N}$, Iwasaki M, Yoshikawa $\mathrm{H}$, Yonenobu K, Kawakami M, Yoshida M, Inoue S, Tani T, Kaneko K, Taguchi T, Imakiire T, Komiya S. Radiographic predictors for the development of myelopathy in patients with ossification of the posterior longitudinal ligament: a multicenter cohort study. Spine (Phila Pa 1976) 2008;15;33(24):2648-50. Crossref 
25. Rao RD, Currier BL, Albert TJ, Bono CM, Marawar SV, Poelstra KA, Eck JC. Degenerative cervical spondylosis: clinical syndromes, pathogenesis, and management. Instr Course Lect 2008;57:447-69.

26. Emery SE. Cervical spondylotic myelopathy: diagnosis and treatment. J Am Acad Orthop Surg 2001;9(6):376-88.

27. Herkowitz HN, Kurz LT, Overholt DP. Surgical management of cervical soft disc herniation. A comparison between the anterior and posterior approach. Spine (Phila Pa 1976) 1990;15(10):1026-30.

28. Wang MC, Kreuter W, Wolfla CE, Maiman DJ, Deyo RA. Trends and variations in cervical spine surgery in the United States: Medicare beneficiaries, 1992 to 2005. Spine (Phila Pa 1976) 2009;20;34(9):955-61. Crossref
29. Riew KD, Buchowski JM, Sasso R, Zdeblick T, Metcalf NH, Anderson PA. Cervical disc arthroplasty compared with arthrodesis for the treatment of myelopathy. J Bone Joint Surg Am 2008;90(11):2354-64. Crossref

30. Heller JG, Sasso RC, Papadopoulos SM, Anderson PA, Fessler RG, Hacker RJ, Coric D, Cauthen JC, Riew DK. Comparison of BRYAN cervical disc arthroplasty with anterior cervical decompression and fusion:clinical and radiographic results of a randomized, controlled, clinical trial. Spine (Phila Pa 1976) 2009;15;34(2):101-7. Crossref 